\title{
Maternal Factors Associated with Levels of Fatty Acids, Specifically n-3 PUFA during Pregnancy: ECLIPSES Study
}

\author{
Estefania Aparicio ${ }^{1,2,+}$, Carla Martín-Grau ${ }^{1,3,+} \mathbb{D}$, Cristina Bedmar ${ }^{1,2}$, Núria Serrat Orus ${ }^{3}\left(\mathbb{D}\right.$, Josep Basora ${ }^{4,5}$, \\ Victoria Arija ${ }^{1,2,4, *}$ and The ECLIPSES Study Group $\ddagger$
}

1 Nutrition and Public Health Unit, Research Group on Nutrition and Mental Health (NUTRISAM), Faculty of Medicine and Health Science, Universitat Rovira i Virgili, 43201 Reus, Spain; estefania.aparicio@urv.cat (E.A.); cgmartin.hj23.ics@gencat.cat (C.M.-G.); cristina.bedmar@urv.cat (C.B.)

2 Pere Virgili Institute for Health Research (IISPV), Universitat Rovira i Virgili, 43003 Tarragona, Spain

3 Clinical Chemistry Laboratory, Catalan Institute of Health (ICS)-Camp de Tarragona-Terres de l'Ebre, Joan XXIII University Hospital in Tarragona, 43005 Tarragona, Spain; nserrat.tarte.ics@gencat.cat

4 Tarragona-Reus Research Support Unit, Jordi Gol Primary Care Research Institute, 43003 Tarragona, Spain; jbasora.tarte.ics@gencat.cat

5 CIBERobn (Center for Biomedical Research in Physiopathology of Obesity and Nutrition), Instituto de Salud Carlos III, 28029 Madrid, Spain

* Correspondence: victoria.arija@urv.cat; Tel.: +34-977759334

+ These authors contributed equally to this work.

$\ddagger$ The ECLIPSES Study Group is provided in the Acknowledgments.

Citation: Aparicio, E.; Martín-Grau, C.; Bedmar, C.; Serrat Orus, N.; Basora, J.; Arija, V.; Maternal Factors Associated with Levels of Fatty Acids, Specifically n-3 PUFA during Pregnancy: ECLIPSES Study. Nutrients 2021, 13, 317. https:// doi.org/10.3390/nu13020317

Received: 15 December 2020

Accepted: 20 January 2021

Published: 22 January 2021

Publisher's Note: MDPI stays neutral with regard to jurisdictional claims in published maps and institutional affiliations.

Copyright: (c) 2021 by the authors. Licensee MDPI, Basel, Switzerland. This article is an open access article distributed under the terms and conditions of the Creative Commons Attribution (CC BY) license (https:// creativecommons.org/licenses/by/ $4.0 /)$.
Abstract: An optimal fatty acid (FA) profile during pregnancy, especially docosahexaenoic acid (DHA) and eicosapentaenoic acid (EPA), is essential for the health of the mother and child. Our aim was to identify the socioeconomic and maternal lifestyle factors associated with serum FA concentration in pregnant women. A longitudinal study was conducted on 479 pregnant women, who were assessed during the first (T1) and third (T3) trimesters of pregnancy. Data on maternal characteristics, food consumption, and lifestyle were collected. Serum FA concentrations were analysed by a gas chromatography-mass spectrometry combination. The multiple linear regression showed that high educational level and older age were significantly associated with higher EPA and DHA concentrations and lower values of $n-6 / n-3$ and arachidonic acid (AA)/EPA in T1 and/or T3. Regarding diet-fish and seafood consumption increased EPA concentration and reduced n-6/n-3 and AA/EPA values in both trimesters, whereas its consumption increased DHA concentration only in T1. Smoking was associated with lower DHA concentration in T1 and higher values of n-6/n-3 ratio in both trimester. Overweight and obesity were associated with higher values of $n-6 / n-3$ ratio and AA/EPA ratio in T1. A statistically non-significant association was observed with saturated fatty acids (SFA) and monounsaturated fatty acids (MUFA). In conclusion, high educational levels, older age, fish, seafood consumption, and/or non-smoking, are factors that influence better omega-3 polyunsaturated fatty acid (n-3 PUFA) profile in both trimesters of pregnancy. Further research is needed to go in-depth into these findings and their health consequences.

Keywords: maternal fatty acid status; polyunsaturated fatty acids; omega-3; pregnancy; lifestyle

\section{Introduction}

Maternal nutritional status has a crucial role in the outcome of mother and child [1-3]. An optimal long-chain n-3 fatty acid status during pregnancy is of particular benefit for cognitive and visual development of the foetus [4-6], and is linked to a reduction in the numbers of preterm births and low birth weights, and a reduced risk of preeclampsia and postpartum depression for the mother $[1,7,8]$. Furthermore, although linoleic acid (LA), omega- 6 polyunsaturated fatty acid (n-6 PUFA), is an essential fatty acid, it is suggested that an adequate balance with $n-3$ is necessary since high levels of $n-6$ before or during 
pregnancy may have negative effects on foetal development and may influence the overall health of offspring in later stages of life $[9,10]$.

Nevertheless, the maternal concentration of polyunsaturated fatty acid (PUFA) varies according to different factors. It is known that the maternal diet is one contribution to fatty acid storage $[8,11,12]$ although it could be affected by other factors that have been less studied. Some studies suggest that several factors, such as age, socioeconomic status, education, smoking, and levels of physical activity can all affect fatty acid levels in pregnant women [8,12-17], although findings differ. For instance, Hoge et al. [13], in a cohort of 112 pregnant women in Belgium, found nationally that, age, educational level, smoking status, physical activity, and docosahexaenoic acid (DHA) supplement intake, all impacted omega-3 polyunsaturated fatty acid (n-3 PUFA) levels in erythrocytes in the first trimester. Similarity, Gellert et al. [14], in a cohort of 213 pregnant women in Germany, found that smoking impacted negatively on omega-3 index in late pregnancy, although this was not found to be linked with age or region. Markus et al. [8] did not find any association with age in a sample of 118 pregnant women in Norway, but found a link between DHA erythrocytes and fish consumption and educational level. Moreover, Pinto et al. [12] reported from Brazil that age, low income, and weekly fish consumption was a predictor of better n-3 serum concentrations in plasma phospholipids. In addition, a recent systematic review assessed the influence of maternal characteristics on DHA and other polyunsaturated fatty acids during pregnancy [18]. That study identified educational level, maternal age, fish consumption, smoking, alcohol intake, and fatty acid desaturase genotype to be associated with omega-3 maternal status. However, not all studies consider all factors together, and have also been carried out at different moments of the pregnancy. Inconsistent results have been reported with n-6 PUFA and maternal factors $[8,12,13,18]$, and to our knowledge, no study has assessed the link between saturated fatty acids (SFA) and monounsaturated fatty acids (MUFA) in a larger sample size than the present study. Consequently, evidence is scarce about the effect of maternal factors on the serum profile of FA as a whole.

Considering the above factors, a better understanding of the factors associated with an inadequate level of fatty acids throughout the pregnancy period would allow population groups at risk to be targeted in order to recommend improvements to their lifestyle and dietary needs. Thus, the aim of this study was to assess the association between the socioeconomic and maternal lifestyle factors early in pregnancy and the maternal fatty acid profile (saturated, monounsaturated and polyunsaturated fatty acids) from a sample of healthy pregnant women in a European Mediterranean country.

\section{Materials and Methods}

\subsection{Study Design and Population}

A prospective study of a cohort of pregnant women who were followed from the first trimester (T1) (around the 12th gestational week) to the third trimester (T3) (the 36th gestational week). The women were recruited from the ECLIPSES study [19,20], which is a randomized triple-blind clinical trial of different doses of iron supplementation ( $20 \mathrm{mg} /$ day, $40 \mathrm{mg} /$ day $80 \mathrm{mg} /$ day), registered in ClinicalTrials.gov identification number NCT03196882, and in the European Union (EU) Clinical Trial Register, EUCTR-2012-00548028. This study was approved by the Clinical Research Ethics Committee of the Jordi Gol Institute for Primary Care Research (IDIAP) and the Pere Virgili Institute for Health Research (IISPV). All participants signed an informed consent. Healthy, pregnant women were recruited during their first prenatal visits at 12 sexual and reproductive health care services (ASSIR) of the Catalan Institute of Health (ICS) in Tarragona, Spain.

Inclusion criteria: healthy woman older than 18 years at $\leq 12$ weeks of gestation, able to understand the local languages (Spanish or Catalan) and the characteristics of the study, and signed the informed consent forms.

Exclusion criteria: multiple pregnancies, taking iron supplements before week 12 of pregnancy, hypersensitivity to egg protein, previous severe disease (immunosuppression), or any chronic disease that could affect nutritional status (cancer, diabetes, malabsorption, 
or liver disease). Fatty acid biochemical status was analysed in a total population study of 479 pregnant women.

\subsection{Data Collection}

Data were collected during T1 and T3 by midwives and nutritionists. The medical history and socioeconomic data obtained were maternal age, ethnicity, education level (primary, secondary, and university studies), estimated date of delivery, planned pregnancy, clinical and obstetric history, and taking multivitamins and micronutrient supplements. Socioeconomic level was classified as low, middle, or high, according to the Catalan classification of occupations [21]. Lifestyle habits were recorded, including smoking habit and alcohol intake, and physical activity levels were assessed by means of the short version of the International Physical Activity Questionnaire (IPAQ-S) [22]. Women were classified as sedentary (including sedentary and irregularly active women) or active (including active and very active women), according to the modified Craig algorithm [22]. In addition, anthropometric measurements obtained were height $(\mathrm{cm})$ and weight $(\mathrm{kg})$, and body mass index (BMI) was calculated at week 12. Thus, women were classified as normal weight $\left(\mathrm{BMI}<25 \mathrm{~kg} / \mathrm{m}^{2}\right)$ and overweight $\left(\mathrm{BMI} \geq 25 \mathrm{~kg} / \mathrm{m}^{2}\right)$, according to the World Health Organization (WHO) criteria [23].

Diet was assessed using a self-administered food frequency questionnaire (FFQ) validated for our population [24]. The questionnaire contains 45 food items and reports on the usual food consumption per week or per month. The food items were classified as fish and seafood, red and processed meat, lean meat, fruit (fresh fruit, preserved fruit), vegetables (salads and vegetables), dairy products, legumes, cereals (breakfast cereals, bread, pasta, and rice), bakery (biscuits, pastries), nuts, sweets (sugar and chocolates), sweetened beverages, alcoholic drinks. Fat consumption, especially oil olive, took into account the amount of oil used for cooking or salad dressings. Food consumption was calculated per gram per day. The consumption of those foods relevant due to their fatty acid content (such as fish and seafood, nuts, red and processed meat, lean meat, eggs, bakery and oil) were included in the analysis. Diet quality was assessed using the Relative Mediterranean Diet Score [25,26], ranging from 0 points (low quality diet) to 18 points (high quality diet). Further information can be found in our previous paper [27]. Women were then classified into two categories: low-medium diet quality (score from 0 to 10) and high diet quality (score from 11 to 18).

\subsection{Sample Collection and Processing of Biochemical Samples of Fatty Acids, and Extraction, Transfer and Storage of Biological Samples}

Venous blood samples were collected at weeks 12 and 36 of pregnancy, after fasting, into $7.5 \mathrm{~mL}$ tubes without an anticoagulant, and remained without mixing for $30 \mathrm{~min}$ at room temperature so as to allow coagulation. The serum was separated by centrifugation, distributed into aliquots of $500 \mu \mathrm{L}$ and stored at $-80^{\circ} \mathrm{C}$ until assays. Samples were stored in the BioBank and thawed at the end of the clinical study and processed simultaneously to minimize inter-batch variation [19].

Medium- and long-chain fatty acids (saturated-, mono- and polyunsaturated) were measured by gas chromatography-mass spectrometry (GC-MS) combination using the 7890A GC coupled to QqQ 7000 Series $^{\circledR}$ (Agilent Technologies Inc., Santa Clara, CA, USA) after their derivation to methyl ester (FAMEs) due to their higher volatility [28]. Briefly, a $50 \mu \mathrm{L}$ plasma sample was mixed with internal standard (IS) solution (Myristic d-27 acid, Merck KGaA, Darmstadt, Germany), chloroform and methanolic hydrochloric acid and incubated at $80{ }^{\circ} \mathrm{C}$ for $2 \mathrm{~h}$. Obtained FAMEs were extracted by a liquid-liquid extraction using hexane and were then injected into the GC-MS system. Chromatographic analysis was based on David et al. [28] to determine the 36 FAMEs included in the Food Industry FAME Mix (Restek Corporation, Pennsylvania, USA). FAMEs were separated into a highpolarity column $(100 \mathrm{~m} \times 250 \mu \mathrm{m} \times 0.25 \mu \mathrm{m})(\mathrm{HP}-88$ column, Agilent Technologies Inc., Santa Clara, CA, USA) using a temperature program of between $140{ }^{\circ} \mathrm{C}$ and $240{ }^{\circ} \mathrm{C}$ at $1 \mathrm{~mL} / \mathrm{min}$ using helium as the carrier gas. Ionisation was carried out by electronic impart 
(70 eV) and mass analyser was operated in Selected Ion Monitoring mode (SIM). The CG-MS system was controlled by the Agilent MassHunter Workstation.

A total of 36 fatty acids were analysed, but only a selection of them is presented, such as the sum of the total saturated (total SFA $=$ C:12 + C:14 + C:16 + C18:0), total monounsaturated (total MUFA $=\mathrm{C} 16: 1 \mathrm{n}-7+\mathrm{C} 18: 1 \mathrm{n}-9$ ), total n-6 polyunsaturated (total n-6 PUFA $=$ C18:2n- $6+C 20: 3 n-6+C 20: 4 n-6$ ) and total $n-3$ polyunsaturated (total n-3 PUFA $=\mathrm{C} 20: 5 \mathrm{n}-3+\mathrm{C} 22: 6 \mathrm{n}-3$ ) fatty acids; further, the ratio of the n- 6 to $n-3$ fatty acids (total n-6 PUFA/total n-3 PUFA) are also presented.

\subsection{Statistical Analysis}

The results were expressed as mean \pm standard deviation (SD) or percentage according to the variable. In this study, z-score analysis was used to detect outlier value in this population data [29]. An absolute value of \pm 3.29 is the standard value used to identify outliers when sample size is $>100$. In other words, any z-score above or below \pm 3.29 is considered as an outlier case [30]. Means between groups were compared using Student's t-test or one-way analysis of variance (ANOVA) adjusted by Bonferroni. Multiple linear regressions were performed in order to identify the association of maternal factors, assessed in T1 and T3, with fatty acid concentration in T1 and T3, respectively. All multiple linear regressions models were performed using the ENTER method and were adjusted for maternal factors, such as educational level, maternal age, BMI, smoking status, alcohol consumption, physical activity, diet quality, food consumption (fish and seafood, nuts, red and processed meat, lean meat, eggs, bakery, and oil). In addition, the models were adjusted for intervention group (iron supplementation of 40,20, or $80 \mathrm{mg} /$ day). Data were processed using the statistical software package SPSS version 25.0 for Windows (SPSS, Chicago, IL, USA). A $p$-value $<0.05$ was considered statistically significant.

\section{Results}

\subsection{Participants' Characteristics}

General characteristics of the pregnant women are given in Table 1. Most women had a medium educational level (38.3\%) and were employed (87.1\%). The mean maternal age was $30.6 \pm 5.01$ years. The participants reported that $15.3 \%$ smoked at the beginning of their pregnancy and $92 \%$ were rated as sedentary by the IPAQ-S questionnaire. The mean score of diet quality was $9.7( \pm 2.6)$ points. In addition, $67.9 \%$ of women reported taking multivitamin and mineral supplementation, of which only one contained DHA or fish oil, and was only consumed by one woman.

\subsection{Influence of Maternal Factors on Fatty Acid Serum Profiles}

Regarding maternal factors shown in Table 2, some of them were related to SFA, n-6 PUFA and MUFA. Overweight or obese women showed a significantly higher concentration of total FAs, specifically SFA and arachidonic acid (AA), total n-6 PUFA and n-6/n-3 ratio in T1, and only SFA in T3. Women with a higher educational level had a significantly greater concentration of total n-3 PUFA (eicosapentaenoic acid (EPA) + DHA) in serum and significantly lower values of $n-6 / n-3$ ratio and AA/EPA ratio compared to women with low and medium educational level in both trimesters of pregnancy. Moreover, older women (34.4 \pm 2.7 years old) had a significantly higher concentration of total n-3 PUFA in serum and lower values of $n-6 / n-3$ ratio and AA/EPA ratio in both trimesters. However, only during T3, older women had a significantly greater concentration of total MUFA compared to younger women. Depending on smoking status, the following differences were observed: women who smoked had a significantly lower concentration of total n-3 PUFA, EPA, and DHA in T1; smokers had a significantly higher concentration of total SFA, total n-6 LA, AA, and total FAs in T3 compared to non-smokers. Moreover, smokers had a higher value of $n-6 / n-3$ ratio in both trimesters. However, there was no observed association with maternal alcohol consumption. 
Table 1. Sociodemographic and lifestyle of pregnant women at baseline and fatty acid biochemical profile at first trimester.

\begin{tabular}{|c|c|}
\hline General Characteristics & Mean (SD) \\
\hline Maternal age $(\text { years })^{a}(n=461)$ & $30.6 \pm 5.01$ \\
\hline \multicolumn{2}{|l|}{ Age group $(\%)$} \\
\hline$<25$ years old & 15.8 \\
\hline $25-30$ years old & 31.2 \\
\hline$>30$ years old & 52.9 \\
\hline \multicolumn{2}{|l|}{ BMI $\left(\mathrm{kg} / \mathrm{m}^{2}\right)(\%)(n=455)$} \\
\hline$<25$ & 62.2 \\
\hline $25-30$ & 25.3 \\
\hline$\geq 30$ & 12.5 \\
\hline \multicolumn{2}{|l|}{ Maternal educational level $(\%)(n=478)$} \\
\hline Low (primary or less) & 30.1 \\
\hline Medium (secondary) & 38.3 \\
\hline High (university or more) & 31.6 \\
\hline \multicolumn{2}{|l|}{ Occupation $(\%)(n=459)$} \\
\hline Student & 2.4 \\
\hline Employed & 87.1 \\
\hline Unemployed & 10.5 \\
\hline \multicolumn{2}{|l|}{ Smoking status $(\%)(n=478)$} \\
\hline Smoker & 15.3 \\
\hline Non-Smoker or Ex-Smoker & 84.7 \\
\hline Maternal alcohol consumption $(\%)(n=445)$ & 14 \\
\hline \multicolumn{2}{|l|}{ Physical Activity $(\%)(n=450)$} \\
\hline Active & 8 \\
\hline Sedentary & 92 \\
\hline Diet Quality (score) & $9.7(2.6)$ \\
\hline \multicolumn{2}{|l|}{ Food groups } \\
\hline Fish and seafood consumption (g/day) & $45.2(30.5)$ \\
\hline Lean meat (g/day) & $39.4(24.7)$ \\
\hline Red and processed meat (g/day) & $57.5(32.3)$ \\
\hline Eggs (g/day) & $17.4(11.3)$ \\
\hline Bakery (g/day) & $33.7(28.2)$ \\
\hline Nuts (g/day) & $3.1(3.8)$ \\
\hline Oil (g/day) & $63.8(15.1)$ \\
\hline
\end{tabular}

a Values are expressed as mean and standard deviation (SD) or \%. Abbreviation: BMI, body mass index.

Multiple linear regression models of the influence of maternal determinants on EPA, and DHA values and total n-3 FA are shown in Table 3 and n-6/n-3 ratio and AA/EPA ratio are described in Table 4. It can be observed that women of a high educational level and an age above 30 years had significantly higher levels of EPA in both trimesters of pregnancy. Likewise, EPA values were higher by fish and seafood consumption in both trimesters $(p<0.05)$. Moreover, high educational level, older age, and fish and seafood consumption is significantly associated with higher values of DHA in T1. Alternatively, smoking reduced the concentration of DHA to around $40 \mu \mathrm{mol} / \mathrm{L}$ in T1 $(p<0.05)$. In T3, ages above 25 or 30 predicted higher values of DHA, although the model is not significant. In the same way, total $\mathrm{n}-3$ is significantly higher in $\mathrm{T} 1$ at higher levels of education, age above 30 years and fish and seafood consumption, whereas it is lower for smokers (Table 3). In T3, only age between 25 and 30 years and older than 30 years is associated with higher values of total n-3 (Table 3). In addition, iron supplementation of $80 \mathrm{mg} /$ day is associated with higher values of EPA, DHA, total n-3 in T1. 
Table 2. Fatty acids serum profile during the first (T1) and third (T3) trimester of pregnancy according to maternal factors.

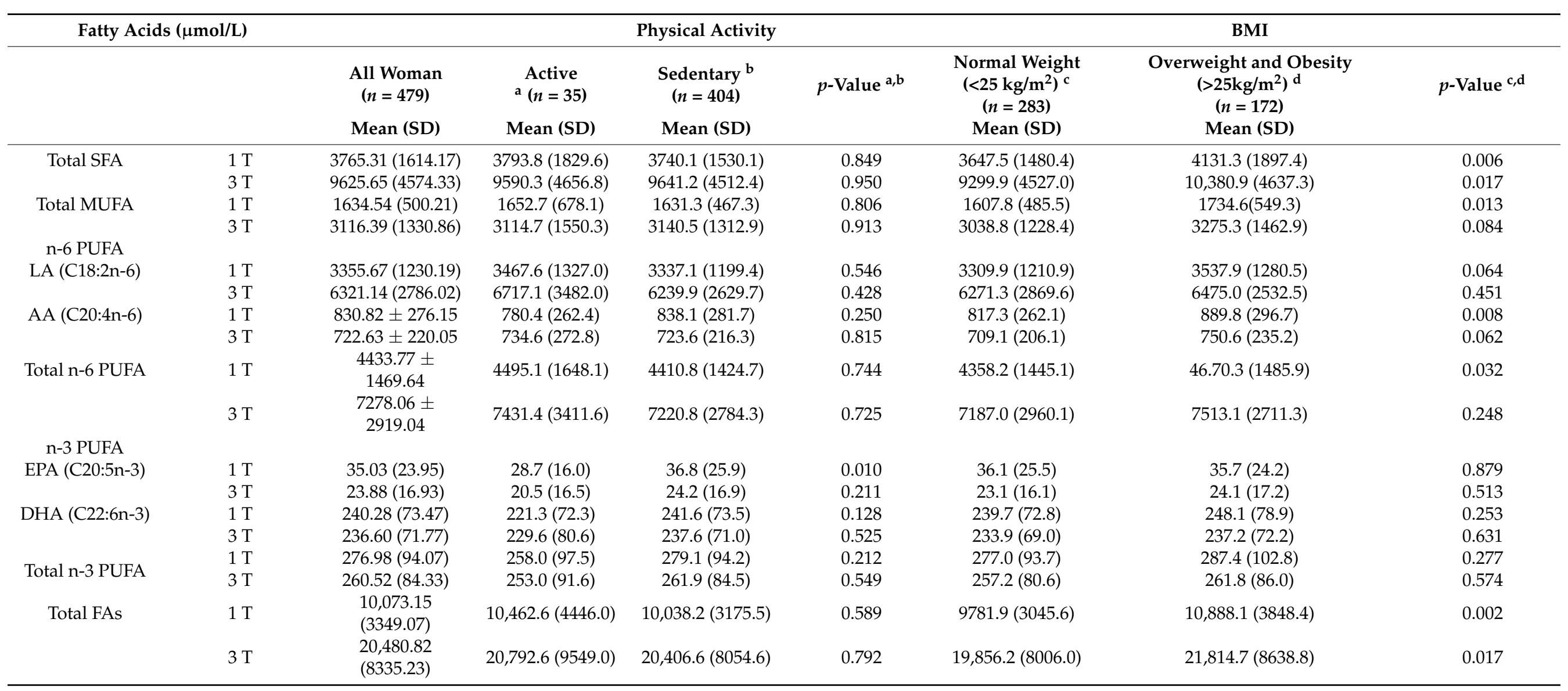


Table 2. Cont.

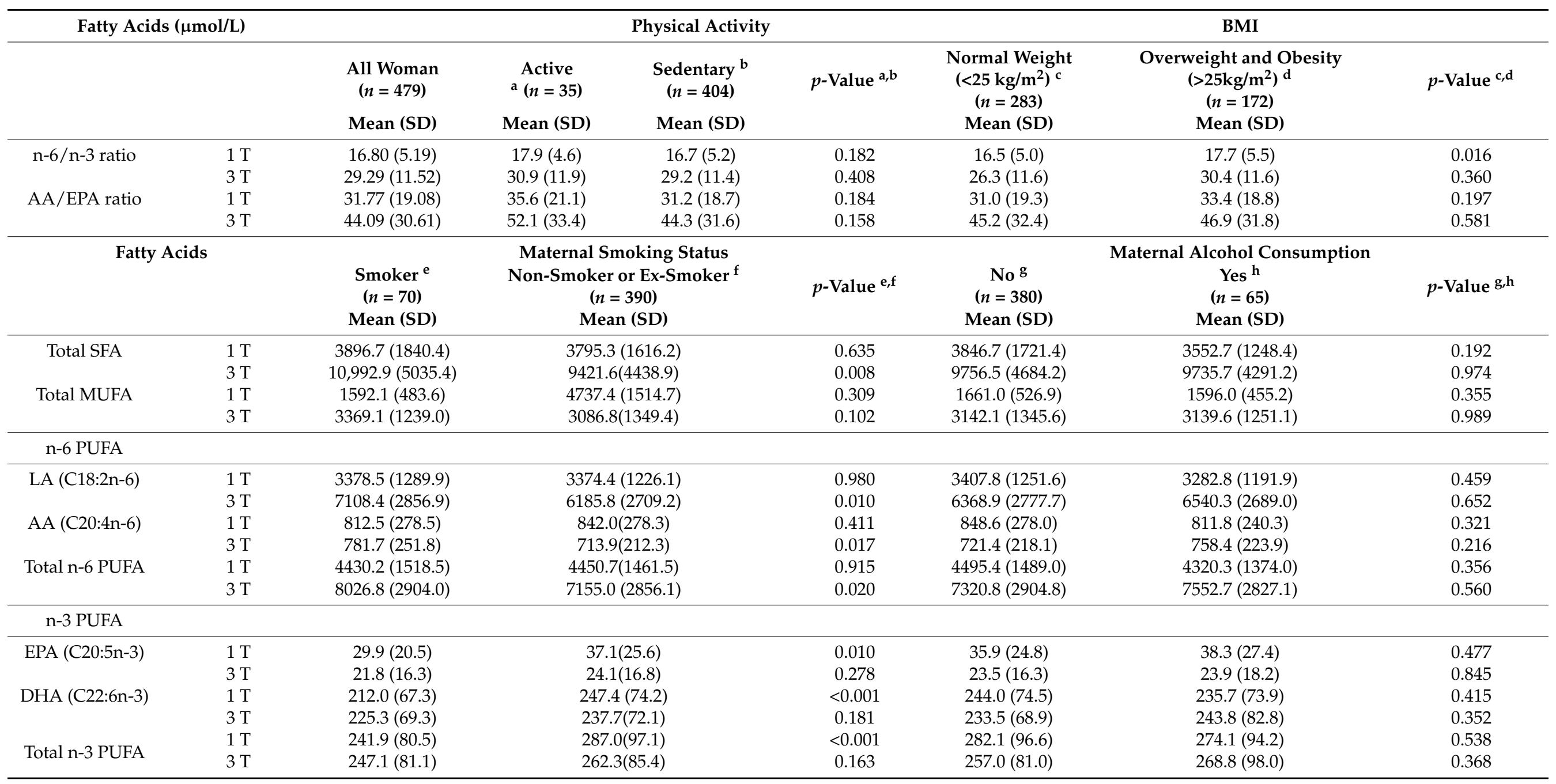


Table 2. Cont.

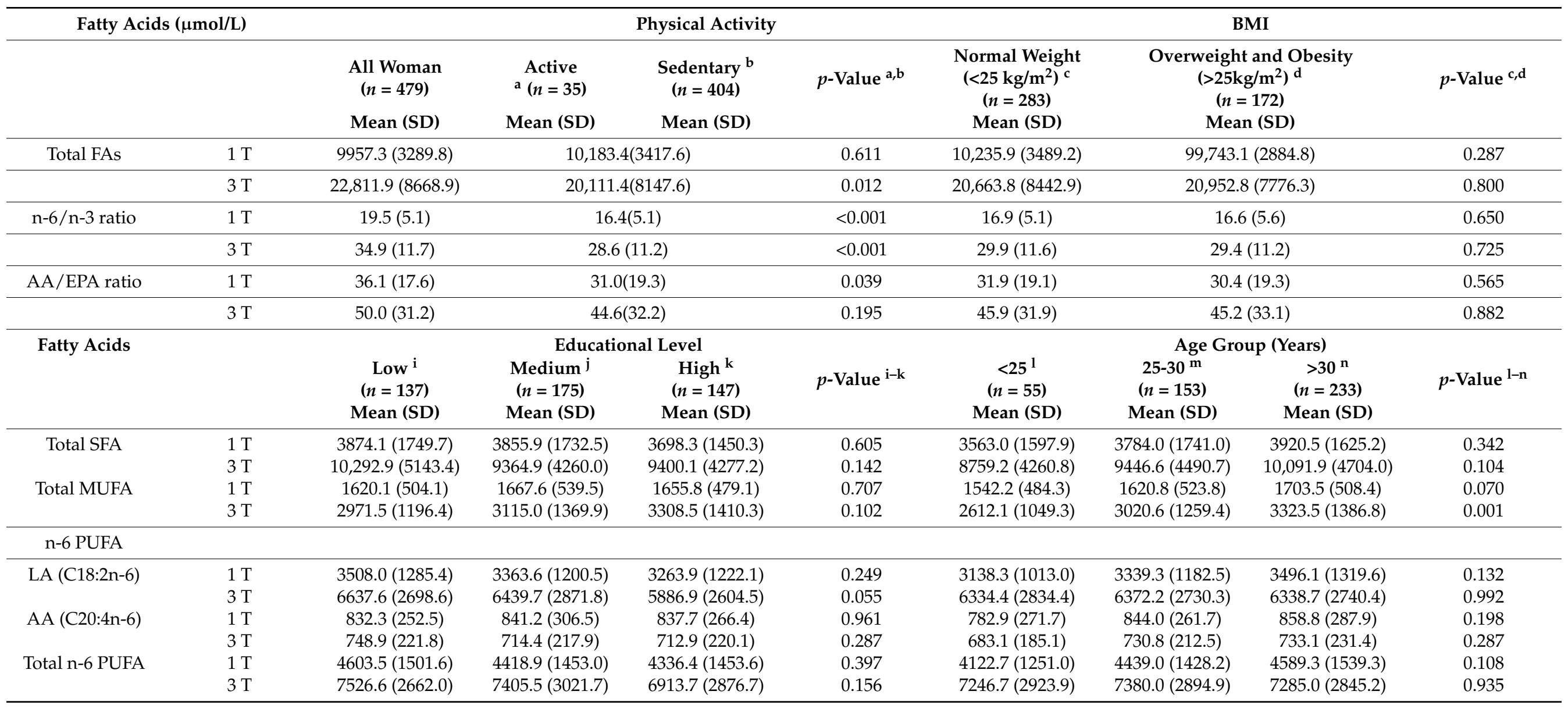


Table 2. Cont.

\begin{tabular}{|c|c|c|c|c|c|c|c|c|c|}
\hline \multirow[t]{2}{*}{ Fatty Acids } & & \multicolumn{4}{|c|}{ Educational Level } & \multicolumn{4}{|c|}{ Age Group (Years) } \\
\hline & & $\begin{array}{c}\text { Low }^{\mathrm{i}} \\
(n=137) \\
\text { Mean (SD) }\end{array}$ & $\begin{array}{c}\text { Medium j } \\
(n=175) \\
\text { Mean (SD) }\end{array}$ & $\begin{array}{c}\text { High }^{\mathrm{k}} \\
(n=147) \\
\text { Mean (SD) }\end{array}$ & $p$-Value ${ }^{\mathrm{i}-\mathrm{k}}$ & $\begin{array}{c}<25^{1} \\
(n=55) \\
\text { Mean (SD) }\end{array}$ & $\begin{array}{c}25-30^{\mathrm{m}} \\
(n=153) \\
\text { Mean (SD) }\end{array}$ & $\begin{array}{c}>30^{\mathrm{n}} \\
(n=233) \\
\text { Mean (SD) }\end{array}$ & $p$-Value ${ }^{1-n}$ \\
\hline \multicolumn{10}{|l|}{ n-3 PUFA } \\
\hline \multirow{2}{*}{ EPA (C20:5n-3) } & $1 \mathrm{~T}$ & $29.0(19.4)$ & $36.1(25.3)$ & $42.5(27.8)$ & $<0.0001$ & $25.7(22.7)$ & $32.6(24.2)$ & $40.6(25.1)$ & $<0.0001$ \\
\hline & $3 \mathrm{~T}$ & $19.6(15.6)$ & $23.4(15.5)$ & $28.1(18.2)$ & $<0.0001$ & $14.8(10.8)$ & $23.0(16.2)$ & $25.9(17.3)$ & $<0.0001$ \\
\hline \multirow[t]{2}{*}{ DHA (C22:6n-3) } & $1 \mathrm{~T}$ & $228.0(70.0)$ & $238.9(71.8)$ & $258.6(78.2)$ & 0.002 & $207.7(57.7)$ & $240.8(79.5)$ & $252.3(73.4)$ & $<0.0001$ \\
\hline & $3 \mathrm{~T}$ & $221.4(66.6)$ & $238.6(70.8)$ & $246.5(75.9)$ & 0.009 & $199.7(60.4)$ & $232.1(66.2)$ & $245.6(72.2)$ & $<0.0001$ \\
\hline Total n-3 PUFA & $3 \mathrm{~T}$ & $241.0(78.6)$ & $262.5(83.4)$ & $275.5(89.4)$ & 0.002 & $215.1(68.3)$ & $256.7(80.6)$ & $271.0(83.8)$ & $<0.0001$ \\
\hline \multirow[t]{2}{*}{ Total FAs } & $1 \mathrm{~T}$ & $10,307.0(3389.4)$ & $10,208.3(3635.0)$ & 9930.1 (3106.4) & 0.623 & 9424.7 (3016.7) & $9959.2(3312.9)$ & $10,538.9(3524.7)$ & 0.057 \\
\hline & $3 \mathrm{~T}$ & $20,891.2(7860.5)$ & $20,493.4(8708.0)$ & $20,207.8(8177.2)$ & 0.783 & $18,711.7$ (6936.9) & $20,099.0(7990.0)$ & $21,362.9(8701.4)$ & 0.066 \\
\hline \multirow[t]{2}{*}{ n-6/n-3 ratio } & $1 \mathrm{~T}$ & $18.7(5.3)$ & $17.2(5.3)$ & $14.7(4.3)$ & $<0.0001$ & $18.4(5.1)$ & $17.6(5.5)$ & $16.2(5.0)$ & 0.005 \\
\hline & $3 \mathrm{~T}$ & $33.1(11.4)$ & $29.9(12.4)$ & $25.7(9.2)$ & $<0.0001$ & $35.6(12.7)$ & $30.1(11.6)$ & $28.1(10.9)$ & $<0.0001$ \\
\hline AA/EPA ratio & $1 \mathrm{~T}$ & $38.0(20.0)$ & $31.9(18.8)$ & $26.1(16.9)$ & $<0.0001$ & $42.4(24.1)$ & $35.1(19.6)$ & $27.7(16.4)$ & $<0.0001$ \\
\hline
\end{tabular}

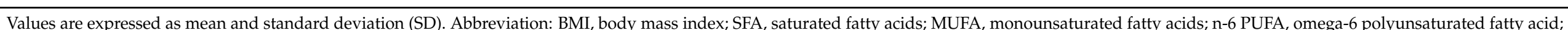

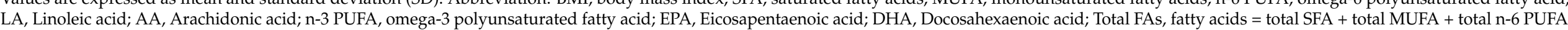

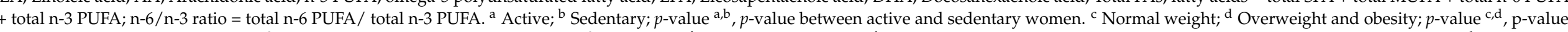

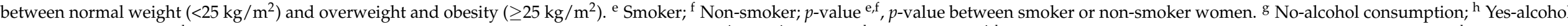

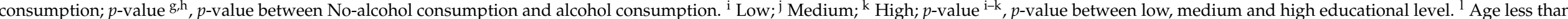

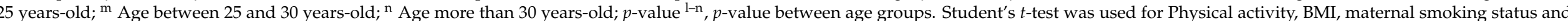
maternal alcohol consumption. One-way analysis of variance (ANOVA) was used for educational level and age group. 
Table 3. Multiple linear regression of potential factors related to maternal serum polyunsaturated fatty acid composition in the first (T1) and third (3T) trimesters of pregnancy.

\begin{tabular}{|c|c|c|c|c|c|c|}
\hline & \multicolumn{3}{|c|}{ Fatty Acids Serum Profile First Trimester } & \multicolumn{3}{|c|}{ Fatty Acids Serum Profile Third Trimester } \\
\hline & B & SE & $p$ & B & SE & $p$ \\
\hline \multicolumn{7}{|l|}{ Eicosapentaenoic acid (EPA) } \\
\hline Constant & 25.13 & 7.86 & 0.002 & 16.46 & 6.84 & 0.017 \\
\hline Low & Ref & - & - & Ref & - & - \\
\hline Medium & 7.65 & 3.32 & 0.022 & 0.49 & 2.62 & 0.851 \\
\hline High & 9.69 & 3.53 & 0.006 & 6.87 & 2.83 & 0.016 \\
\hline \multicolumn{7}{|l|}{ Age group } \\
\hline $25-30$ years & 3.75 & 4.38 & 0.392 & 6.79 & 3.24 & 0.038 \\
\hline$\geq 30$ years & 9.93 & 4.22 & 0.019 & 8.80 & 3.11 & 0.005 \\
\hline $\operatorname{BMI}\left(0:<25 \mathrm{~kg} / \mathrm{m}^{2}, 1: \geq 25 \mathrm{~kg} / \mathrm{m}^{2}\right)$ & -1.21 & 2.80 & 0.665 & 0.82 & 2.60 & 0.751 \\
\hline Physical activity (0: sedentary, 1 : active) & -9.58 & 4.51 & 0.035 & -2.02 & 2.51 & 0.421 \\
\hline Smoking (0: non-smoke, 1: smoker) & -6.61 & 3.72 & 0.076 & 2.85 & 2.70 & 0.292 \\
\hline Maternal alcohol consumption (0: no, 1 : yes) & -0.86 & 4.67 & 0.854 & 0.61 & 3.79 & 0.871 \\
\hline Fish and seafood consumption (g/day) & 0.15 & 0.04 & 0.001 & 0.14 & 0.40 & $<0.001$ \\
\hline Bakery consumption (g/day) & -0.1 & 0.04 & 0.037 & -0.05 & 0.041 & 0.204 \\
\hline \multicolumn{7}{|l|}{$\begin{array}{l}\text { Intervention Group } \\
\text { (iron supplementation dosage) }\end{array}$} \\
\hline $40 \mathrm{mg} /$ day & Ref & - & - & Ref & - & - \\
\hline $20 \mathrm{mg} /$ day & 1.70 & 3.72 & 0.648 & -2.10 & 2.67 & 0.432 \\
\hline \multirow[t]{2}{*}{$80 \mathrm{mg} /$ day } & 7.97 & 3.07 & 0.010 & -1.78 & 2.47 & 0.473 \\
\hline & $\mathrm{R}^{2} \mathrm{CX} 100=10.3$ & $\mathrm{~F}_{18,328}=3.21$ & $p<0.001$ & $\mathrm{R}^{2}{ }_{\mathrm{CX} 100}=8.8$ & $\mathrm{~F}_{18,234}=2.25$ & $p=0.002$ \\
\hline \multicolumn{7}{|l|}{ Docosahexaenoic acid (DHA) } \\
\hline Constant & 212.64 & 22.29 & $<0.001$ & 241.16 & 30.48 & $<0.001$ \\
\hline \multicolumn{7}{|l|}{ Educational level } \\
\hline Low & Ref & - & - & Ref & - & - \\
\hline Medium & 10.29 & 9.50 & 0.280 & -2.09 & 11.06 & 0.850 \\
\hline High & 22.45 & 10.01 & 0.026 & 11.54 & 12.04 & 0.339 \\
\hline \multicolumn{7}{|l|}{ Age group } \\
\hline$<25$ years & Ref & - & - & Ref & - & - \\
\hline $25-30$ years & 19.46 & 12.53 & 0.121 & 29.46 & 13.73 & 0.033 \\
\hline$>30$ years & 28.01 & 12.07 & 0.021 & 41.26 & 13.23 & 0.002 \\
\hline $\operatorname{BMI}\left(0:<25 \mathrm{~kg} / \mathrm{m}^{2}, 1: \geq 25 \mathrm{~kg} / \mathrm{m}^{2}\right)$ & 11.37 & 7.97 & 0.154 & -4.65 & 10.77 & 0.666 \\
\hline
\end{tabular}


Table 3. Cont.

\begin{tabular}{|c|c|c|c|c|c|c|}
\hline & \multicolumn{3}{|c|}{ Fatty Acids Serum Profile First Trimester } & \multicolumn{3}{|c|}{ Fatty Acids Serum Profile Third Trimester } \\
\hline & B & SE & $p$ & B & SE & $p$ \\
\hline Physical activity (0: sedentary, 1 : active) & -20.06 & 13.10 & 0.127 & -10.98 & 11.78 & 0.352 \\
\hline Smoking (0: non-smoke, 1: smoker) & -39.93 & 10.65 & $<0.001$ & -2.06 & 11.43 & 0.857 \\
\hline Fish and seafood consumption (g/day) & 0.34 & 0.13 & 0.011 & 0.223 & 0.172 & 0.195 \\
\hline \multicolumn{7}{|l|}{$\begin{array}{l}\text { Intervention Group } \\
\text { (iron supplementation dosage) }\end{array}$} \\
\hline $40 \mathrm{mg} /$ day & Ref & - & - & Ref & - & - \\
\hline \multirow[t]{2}{*}{$80 \mathrm{mg} /$ day } & 22.46 & 8.66 & 0.010 & -7.05 & 10.51 & 0.503 \\
\hline & $\mathrm{R}^{2}{ }_{\mathrm{CX} 100}=10.20$ & $\mathrm{~F}_{18,334}=3.22$ & $p<0.001$ & $\mathrm{R}^{2} \mathrm{CX100}=3.6$ & $\mathrm{~F}_{18,236}=1.52$ & $p=0.084$ \\
\hline \multicolumn{7}{|l|}{ Total n-3 PUFA } \\
\hline \multicolumn{6}{|l|}{ Educational level } & $<0.001$ \\
\hline Low & Ref & - & - & Ref & - & - \\
\hline Medium & 17.10 & 12.24 & 0.163 & 1.78 & 13.13 & 0.892 \\
\hline High & 30.08 & 12.96 & 0.021 & 16.47 & 14.31 & 0.251 \\
\hline \multicolumn{7}{|l|}{ Age group } \\
\hline $25-30$ years & 24.10 & 16.19 & 0.132 & 39.82 & 16.31 & 0.015 \\
\hline$>30$ years & 41.49 & 15.58 & 0.008 & 51.88 & 15.71 & 0.001 \\
\hline $\operatorname{BMI}\left(0:<25 \mathrm{~kg} / \mathrm{m}^{2}, 1: \geq 25 \mathrm{~kg} / \mathrm{m}^{2}\right)$ & 10.66 & 10.28 & 0.301 & -10.43 & 12.83 & 0.417 \\
\hline Physical activity (0: sedentary, 1 : active) & -22.93 & 16.69 & 0.170 & -18.41 & 12.53 & 0.143 \\
\hline Smoking (0: non-smoke, 1: smoker) & -48.75 & 13.75 & $<0.001$ & 0.763 & 13.63 & 0.955 \\
\hline Maternal alcohol consumption (0: no, 1 : yes) & -20.63 & 17.24 & 0.232 & -4.01 & 19.15 & 0.834 \\
\hline Fish and seafood consumption (g/day) & 0.489 & 0.175 & 0.006 & 0.35 & 0.20 & 0.086 \\
\hline \multicolumn{7}{|l|}{ Intervention Group } \\
\hline $40 \mathrm{mg} /$ day & Ref & - & - & Ref & - & - \\
\hline $20 \mathrm{mg} /$ day & -3.17 & 13.75 & 0.817 & -18.91 & 13.50 & 0.163 \\
\hline \multirow[t]{2}{*}{$80 \mathrm{mg} /$ day } & 30.37 & 11.21 & 0.007 & -11.35 & 12.44 & 0.363 \\
\hline & $\mathrm{R}^{2} \mathrm{CX} 100=11.00$ & $\mathrm{~F}_{18,333}=3.41$ & $p<0.001$ & $\mathrm{R}^{2} \mathrm{CX} 100=5.0$ & $\mathrm{~F}_{18,236}=1.74$ & $p=0.033$ \\
\hline
\end{tabular}

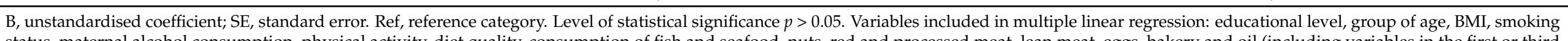

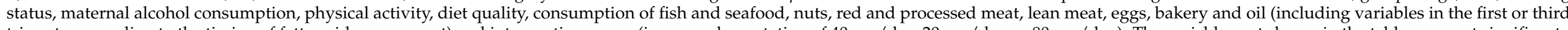

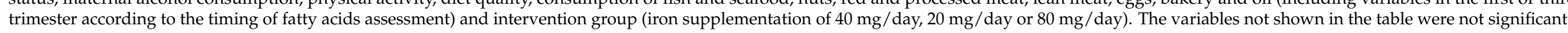


Table 4. Multiple linear regression of potential factors related to maternal serum n-6/n-3 and AA/EPA ratios.

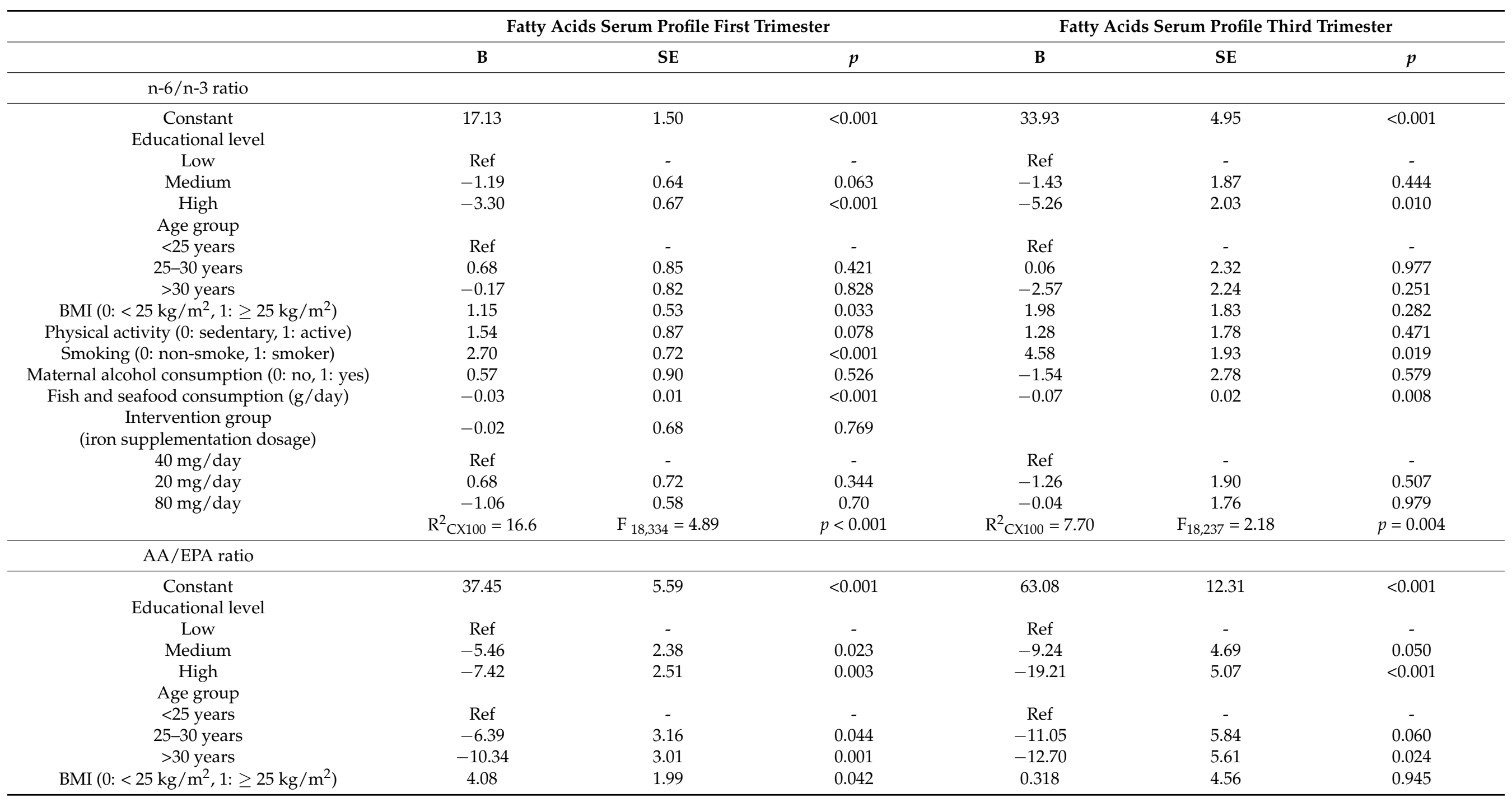


Table 4. Cont.

\begin{tabular}{|c|c|c|c|c|c|c|}
\hline & \multicolumn{3}{|c|}{ Fatty Acids Serum Profile First Trimester } & \multicolumn{3}{|c|}{ Fatty Acids Serum Profile Third Trimester } \\
\hline & B & SE & $p$ & B & SE & $p$ \\
\hline Physical activity (0: sedentary, 1 : active) & 5.73 & 3.20 & 0.074 & 0.31 & 4.56 & 0.945 \\
\hline Smoking (0: non-smoke, 1: smoker) & 3.82 & 2.64 & 0.148 & -2.16 & 4.85 & 0.656 \\
\hline Fish and seafood consumption (g/day) & -0.16 & 0.03 & $<0.001$ & -0.26 & 0.70 & $<0.001$ \\
\hline Bakery consumption (g/day) & 0.05 & 0.03 & 0.132 & 0.19 & 0.073 & 0.008 \\
\hline \multicolumn{7}{|l|}{$\begin{array}{l}\text { Intervention Group } \\
\text { (iron supplementation dosage) }\end{array}$} \\
\hline $20 \mathrm{mg} /$ day & -0.13 & 2.65 & 0.959 & -1.07 & 4.86 & 0.825 \\
\hline \multirow[t]{2}{*}{$80 \mathrm{mg} /$ day } & -4.35 & 2.16 & 0.045 & -0.198 & 4.38 & 0.964 \\
\hline & $\mathrm{R}^{2} \mathrm{CX100}=16.9$ & $\mathrm{~F}_{18,329}=7.23$ & $p<0.001$ & $\mathrm{R}^{2} \mathrm{CX100}=13.5$ & $\mathrm{~F}_{18,233}=3.17$ & $p<0.001$ \\
\hline
\end{tabular}

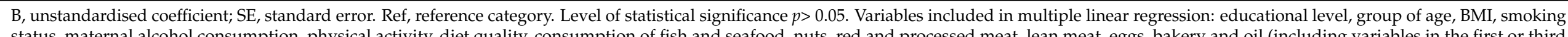

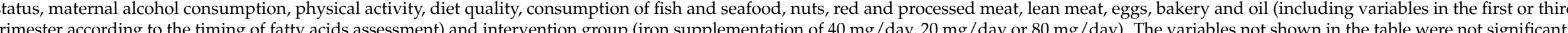


Regarding $n-6 / n-3$ ratio and AA/EPA, high educational level in $\mathrm{T} 1$ and $\mathrm{T} 3$ reduces the $\mathrm{n}-6 / \mathrm{n}-3$ ratio. On the other hand, medium and high educational level and age older than 25 or 30 decreased AA/EPA ratio in both trimesters (except for age group between 25 and 30 in T3). Moreover, fish and seafood consumption is associated with significantly lower values of $n-6 / n-3$ ratio and AA/EPA in both trimesters. As expected, smoking increased the $\mathrm{n}-6 / \mathrm{n}-3$ ration by around 2 and 4 points in T1 and T3, respectively. Moreover, overweight or obesity increased the $n-6 / n-3$ ratio and AA/EPA ratio, while iron supplementation of $80 \mathrm{mg} /$ day reduced AA/EPA ratio in T1 (Table 4). In addition, there was no statistically significant association between maternal factors and AA concentration (data not shown).

\section{Discussion}

In this prospective study of Mediterranean pregnant women, we identified the main maternal factors that affect the n-3 PUFA and their balance with n-6 PUFA. Specifically, women of 25 or 30 years old and/or with medium or high educational level showed better levels of fatty acids, with a greater n-3 fatty acids serum concentration and lower values of n- $6 / n-3$ and AA/EPA ratio in both the first (T1) and third (T3) trimesters. Moreover, higher fish and seafood consumption is favourably linked with higher EPA and DHA concentrations and with a lower $n-6 / n-3$ ratio and AA/EPA in both trimesters, except for DHA, which was not linked in T3. However, smoking reduced DHA concentration and increased $n-6 / n-3$ ratio T1, but only $n-6 / n-3$ in T3. Practically none of the maternal factors assessed were related to SFA, apart from overweight and obesity status, or MUFA, apart from the older age of the mother in T3.

To our knowledge, there are few studies that have assessed maternal and lifestyle factors associated with serum fatty acid concentrations in a pregnant population, DHA and EPA being of great importance for mother and child health [31]. Moreover, an adequate balance between $n-3$ and $n-6$ is a critical factor for health because the n-6 PUFA compete with the n-3 PUFA by the metabolism of desaturation enzymes and, consequently, influences the kind of eicosanoid generated [32]. It is relevant to evaluate the association of FA serum concentrations and the maternal factors related throughout the whole pregnancy period. Specifically, diet is one of the most studied factors related to FA status. Nowadays, the occidental diet tends not to sufficiently provide n-3 PUFA, and the n-6 PUFA intake tends to be higher than recommendations [33,34]. The main source of n-3 PUFA are fish and seafood, which could be crucial contributors to an adequate level of n-3 PUFA and the n- $6 / n-3$ and AA/EPA ratios during pregnancy, as has been reported previously $[8,11,12,18]$. As expected, our results showed that fish and seafood consumption positively predicted greater serum concentrations of EPA and DHA and low values of n-6/n-3 ratio and AA/EPA ratio in T1. Within estimations based on our model, it was pointed out that for each fish serving (150 $\mathrm{g}$ of weight approximately), the concentration of EPA and DHA increases by 22.5 and $51 \mu \mathrm{mol} / \mathrm{L}$ respectively, improving their concentrations considerably. However, these associations were only maintained for EPA and n- $6 / n-3$ and AA/EPA ratios during T3, but not for DHA concentrations in agreement with Bonham et al. [35]. This might be due to the fact that DHA could be regulated by different biosynthesis or mobilisation mechanism [34]. For instance, hormonal changes that occur during pregnancy, such as the increase in oestrogen that supports conversion of alpha-linolenic acid (ALA) to DHA [36-38]. Another reason might be that in T3 there is a high mobilisation of DHA from the maternal fat store to the foetus in order to stimulate high brain maturation. In addition, bakery food, which is usually manufactured with vegetable oils rich in n-6, can predict high AA/EPA ratios. In view of these findings, an optimal n-3 PUFA concentration and n- $6 / n-3$ and AA/EPA ratios at the beginning of the pregnancy are needed to assure an adequate concentration and store throughout the pregnancy and even the lactation period [8]. Therefore, to acquire healthy eating habits, including fish and seafood consumption, it is essential to achieve an optimal EPA and DHA concentration at the beginning and during pregnancy, which could contribute to improving child neurodevelopment and protection from autism-spectrum traits [39-41]. In particular, higher maternal n-6/n-3 ratios and higher maternal concentra- 
tions of total n-6 PUFA are among potential environmental risk factors that are associated to autism spectrum disorder [39,42] and immune system disease [43]. The placental fat transport is driven by a concentration gradient as the foetus has substantially lower fat concentrations, indicating a preferential transfer of n-6 PUFA [42]. The consequence is an imbalance between n-3 and n-6 PUFA levels that may contribute to offspring diseases. We found that age and educational level are also the common contributors to fatty acid concentrations in maternal serum throughout pregnancy. Our results show that those women over 25 years of age, or with medium or high educational level in particular, showed high values of EPA and DHA and low values of n-6/n-3 and AA/EPA ratio. Some authors have not reported a significant association between age or educational level and DHA or total n-3 PUFA [8,14], although similar findings to ours regarding age have been reported in different countries [12,13,15,17]. Likewise, Pinto et al. [12] found that low income correlated negatively with the n-6/-n-3 ratio, and other studies have reported a positive correlation between educational level and levels of DHA, total n-3 PUFA and a negative correlation with AA/EPA ratio $[13,16]$. Although some research has shown that older women with a higher educational level tend to consume more n-3 or fish and seafood during pregnancy $[44,45]$, and/or showed high adherence to diet quality $[27,46,47]$, in our study only observed significant differences on fish and seafood consumption by age group (age group: <25 years old: $36.3 \pm 21.6 ; 25-30$ years old: $46.1 \pm 31.6 ;>30$ years old: $47.2 \pm 30.5 ; p=0.049$ ). In addition, women with medium or high educational levels might have greater nutritional knowledge $[48,49]$. Lower educational levels and younger ages might be linked to lower incomes and may have less access to food sources of $n-3$ PUFA (fish and seafood), which tend to be expensive [12,50,51]. In agreement with our results, Nordgren et al. [51] indicates that socioeconomically disadvantaged populations (low educational level and low income) are particularly at risk for even lower levels of omega-3 intake. Regarding n-6 PUFA, two studies also report no link with age [8] or educational level [13] in agreement with our results. In contrast, two studies observed a positive link with age $[12,16]$, but others showed a negative correlation with age $[13,16]$ and/or education level [8].

Nutritional status could be a potential factor, although the literature shows controversial results [11-15]. Lesch et al. [11] found overweight women showed higher concentrations of AA and n-3 PUFA. However, our results show that overweight or obesity status is associated to higher concentrations of SFA, AA andn-3/n-6 and AA/EPA ratio. It can be hypothesized that, in our sample, the higher FA level might due to greater food consumption, especially of those foods rich in n-6 FA, which could interfere in the conversion of EPA. Moreover, excessive maternal adiposity could alter the placental transfer of FA [52].

Another of our principal relevant findings is that pregnant women who smoke showed low levels of DHA, total $n-3$ and high n-6/n-3 ratio only in T1. In particular, smoking predicted a reduction of around $40 \mu \mathrm{mol} / \mathrm{L}$ of DHA. These results confirm recent findings in the omega-3 index in erythrocyte or in total n-3 in serum fatty acid $[12-15,17,53]$. This influence is possibly caused by the adverse effect of smoking on the conversion process of ALA to DHA [54,55]. This link with DHA and n-3 was not observed in T3, probably by the mechanism of transferring DHA maternal stores to foetus. However, it was shown that smoking increased the n- $6 / n-3$ ratio, which suggests that smoking could affect the fatty acid profile some another way since it might alter the conversion rate of n- 6 to eicosanoids, such as prostaglandin E2 $[55,56]$. This shows an anti-inflammatory effect and has a crucial role in the regulation of delivery [57]. In fact, smoking during pregnancy has been shown as a risk factor for premature delivery [58]; therefore, advising a mother to quit smoking in pregnancy could improve the FA profile throughout gestation and prevent negative outcomes for mother and child.

Regarding another unhealthy lifestyle habit, some studies have found that maternal alcohol consumption has been associated with worse n- 6 and n-3 FA concentrations $[12,15,16,18,53]$ since it could impair lipid metabolism [59]. However, our results did not find any significant association, probably due to the fact that the amount of alcohol 
consumption in our sample is low (3.01 g/day \pm 15.2$)$ in comparison to women who consume alcohol frequently [16] or moderately-heavily [53].

It should be noted that iron supplementation of $80 \mathrm{mg}$ was associated to higher concentration of EPA, DHA total n-3 and a lower AA/EPA ratio. There appears to be a physiological relationship between the metabolism and utilization of iron and that of fatty acids, although it is not yet clear [60].

Our findings provide crucial information for knowing and identifying maternal factors related to serum concentrations of FA and developing an intervention program focused on modifiable factors, such as dietary and smoking habits, and targeting high-risk groups. Our study has several strengths. It is longitudinal, which enabled us to study the concentrations of fatty acid and the maternal factors throughout the pregnancy period. Secondly, all procedures in data collection and sample analyses were intensively monitored. Moreover, we included in our analysis different types of FA. Indeed, this is the first study that has analysed SFA and MUFA with several maternal factors. Another strength is the greater sample size in comparison with other studies [12-14].

However, our study also has several limitations. Firstly, due to the lack of references or range values, we were not able to apply a cut-off value to describe the intensity of how maternal factors affect the fatty acid profile and which potential consequences of lower n-3 status can appear in the mother and child. Further studies regarding the whole FA profile are encouraged. On the other hand, although we had data on fatty acid concentrations in plasma rather than red blood cells, we consider that our results are not affected because it has been shown that fatty acid concentrations in plasma and red blood cells are highly correlated [61-63] and studies that use both biochemical parameters obtained similar results [15]. Finally, we were unable to evaluate other environmental and genetic factors that might impact on serum fatty acid concentrations during pregnancy. For instance, gene coding for proteins involved in uptake, metabolism, transport and restructuration, especially, the fatty acid desaturase (FADS) gene cluster, which is related to desaturation steps in the n-3 and n-6 fatty acids might also contribute [64].

\section{Conclusions}

In conclusion, educational level or age are common factors that affected EPA, DHA, and the $n-6 / n-3$ and AA/EPA in both trimesters. Overweight and obesity predicted higher values of n-6/n-3 ratio and AA/EPA ratio in the first trimester. Lifestyle habits, such as fish and seafood consumption, increased EPA and AA/EPA ratio in both trimesters, whereas DHA was modified by fish and seafood consumption in the first trimester. Smoking showed an impairment in the fatty acid profile: a decrease in DHA in the first trimester and an increase of n-6/n-3 in both trimesters. However, no relevant association was found with SFA and MUFA. Therefore, nutritional intervention and advice to stop smoking geared to pregnant women, especially those who are younger than 25 years-old, with low educational levels, or are overweight or obese, could improve the FA serum profiles, especially n-3 PUFA, as it may benefit their health and the health of their newborns. Further research is needed to go in-depth into these findings and their health consequences.

Author Contributions: Conceptualization, V.A., J.B.; formal analysis, C.M.-G., E.A.; data curation, E.A., C.M.-G., V.A., C.B., N.S.O.; Investigation, V.A.; writing-original draft preparation, E.A., C.M.-G., V.A.; writing-review and editing, E.A., C.M.-G., V.A., J.B. All authors have read and agreed to the published version of the manuscript.

Funding: The study ECLIPSES was financially supported by a grant (PI12/02777) from the Health Research Fund of the Ministry of Health and Consumption (Madrid, Spain) (Instituto de Salud Carlos III, Fondo de Investigación Sanitaria, Ministerio de Sanidad y Consumo) and co-funded by European Union (ERDF/ESF, "A way to make Europe" / "Investing in your future"). The funding bodies played no part in the design of the study, collection and interpretation of data, or decision to publish. 
Institutional Review Board Statement: The study was conducted according to the guidelines of the Declaration of Helsinki, and approved by the Clinical Research Ethics Committee of the Jordi Gol Research Institute in Primary Care [Instituto de Investigación en Atención Primaria; IDIAP] and the Spanish Agency for Medicines and Health Products [Agencia Española del Medicamento y Productos Sanitarios; AEMPS] (AEMPS IJG-FER-2012 on 9 July 2018).

Informed Consent Statement: Informed consent was obtained from all subjects involved in the study.

Acknowledgments: We thank the Jordi Gol Research Institute in Primary Care (Institut d' Investigació en Atenció Primària; IDIAP) for their guidance regarding ethical matters. We thanks to entities and participants in ECLIPSES study: Research Group in Nutrition and Mental Health (NUTRISAM), Universitat Rovira i Virgili, Reus, Spain (Victoria Arija, Josepa Canals, Estefanía Aparicio, Núria Aranda, Cristina Bedmar, Carmen Hernández, Lucía Iglesias, Cristina Jardí, Núria Voltas). Sexual and Reproductive Health Care Services (ASSIR) of Tarragona, Spain (Francesc Fargas, Francisca Ruiz, Gemma March, Susana Abajo) and team of midwives recruiting for the study (Irene Aguilar, Sònia Aguiles, Rosa Alzúria, Judit Bertrán, Carmen Burgos, Elisabet Bru, Montserrat Carreras, Beatriz Fernández, Carme Fonollosa, María Leiva, Demetria Patricio, Teresa Pinto, María Ramírez, Eusebia Romano, Inés Sombreo). Research support Unit-Tarragona (Josep Basora, Meritxell Pallejà) and Central Unit-Barcelona (Rosa Morros) of the Institut d'Atenció Primària IDIAP Jordi Gol, Institut Català de la Salut. Laboratory of Institut Català de la Salut (ICS), University Hospital of Tarragona Joan XXIII, Tarragona, Spain (Núria Serrat, Carla Martín). Finally, we thank the Centre for Omic Sciences (COS) Joint Unit of the Universitat Rovira i Virgili-Eurecat for their contribution to chromatographic and mass spectrometry analysis (Núria Canela, Elisabet Foguet, Marc Riu, Pol Herrero, and Antoni del Pino).

Conflicts of Interest: The authors declare no conflict of interest.

\section{References}

1. Mousa, A.; Naqash, A.; Lim, S. Macronutrient and Micronutrient Intake during Pregnancy: An Overview of Recent Evidence. Nutrients 2019, 11, 443. [CrossRef] [PubMed]

2. Koletzko, B.; Brands, B.; Grote, V.; Kirchberg, F.F.; Prell, C.; Rzehak, P.; Uhl, O.; Weber, M. Long-Term Health Impact of Early Nutrition: The Power of Programming. Ann. Nutr. Metab. 2017, 70, 161-169. [CrossRef] [PubMed]

3. Koletzko, B.; Godfrey, K.M.; Poston, L.; Szajewska, H.; Van Goudoever, J.B.; De Waard, M.; Brands, B.; Grivell, R.M.; Deussen, A.R.; Dodd, J.M.; et al. Nutrition during pregnancy, lactation and early childhood and its implications for maternal and long-term child health: The early nutrition project recommendations. Ann. Nutr. Metab. 2019, 74, 93-106. [CrossRef] [PubMed]

4. Birch, E.E.; Carlson, S.E.; Hoffman, D.R.; Fitzgerald-Gustafson, K.M.; Fu, V.L.; Drover, J.R.; Castañeda, Y.S.; Minns, L.; Wheaton, D.K.H.; Mundy, D.; et al. The DIAMOND (DHA intake and measurement of neural development) study: A doublemasked, randomized controlled clinical trial of the maturation of infant visual acuity as a function of the dietary level of docosahexaenoic acid. Am. J. Clin. Nutr. 2010, 91, 848-859. [CrossRef] [PubMed]

5. Campoy, C.; Escolano-Margarit, M.; Anjos, T.; Szajewska, H.; Uauy, R. Omega 3 fatty acids on child growth, visual acuity and neurodevelopment. Br. J. Nutr. 2012, 107, S85-S106. [CrossRef]

6. Koletzko, B.; Lien, E.; Agostoni, C.; Böhles, C.; Campoy, C.; Cetin, I.; Decsi, T.; Dudenhausen, J.W.; Dupont, C.; Forsyth, S.; et al. The roles of long-chain polyunsaturated fatty acids in pregnancy, lactation and infancy: Review of current knowledge and consensus recommendations. J. Perinat. Med. 2008, 36, 5-14. [CrossRef]

7. Hoge, A.; Tabar, V.; Donneau, A.F.; Dardenne, N.; Degée, S.; Timmermans, M.; Nisolle, M.; Guillaume, M.; Castronovo, V. Imbalance between omega- 6 and omega-3 polyunsaturated fatty acids in early pregnancy is predictive of postpartum depression in a Belgian cohort. Nutrients 2019, 11, 876. [CrossRef]

8. Markhus, M.W.; Rasinger, J.D.; Malde, M.K.; Frøyland, L.; Skotheim, S.; Braarud, H.C.; Stormark, K.M.; Graff, I.E. Docosahexaenoic Acid Status in Pregnancy Determines the Maternal Docosahexaenoic Acid Status 3-, 6- and 12 Months Postpartum. Results from a Longitudinal Observational Study. PLoS ONE 2015, 10, e0136409. [CrossRef]

9. Shrestha, N.; Sleep, S.L.; Cuffe, J.S.M.; Holland, O.J.; Perkins, A.V.; Yau, S.Y.; McAinch, A.J.; Hryciw, D.H. Role of omega-6 and omega-3 fatty acids in fetal programming. Clin. Exp. Pharmacol. Physiol. 2020, 47, 907-915. [CrossRef]

10. Shrestha, N.; Holland, O.J.; Kent, N.L.; Perkins, A.V.; McAinch, A.J.; Cuffe, J.S.M.; Hryciw, D.H. Maternal High Linoleic Acid Alters Placental Fatty Acid Composition. Nutrients 2020, 12, 2183. [CrossRef]

11. Lepsch, J.; Vaz, J.S.; Moreira, J.D.; Pinto, T.J.; Soares-Mota, M.; Kac, G. Food frequency questionnaire as an indicator of the serum composition of essential n-3 and n-6 polyunsaturated fatty acids in early pregnancy, according to body mass index. J. Hum. Nutr. Diet. 2015, 28, 85-94. [CrossRef] [PubMed]

12. Pinto, T.J.; Farias, D.R.; Rebelo, F.; Lepsch, J.; Vaz, J.S.; Moreira, J.D.; Cunha, G.M.; Kac, G. Lower inter-partum interval and unhealthy life-style factors are inversely associated with n-3 essential fatty acids changes during pregnancy: A prospective cohort with Brazilian women. PLoS ONE 2015, 10, e0121151. [CrossRef] [PubMed] 
13. Hoge, A.; Bernardy, F.; Donneau, A.F.; Dardenne, N.; Degée, S.; Timmermans, M.; Nisolle, M.; Guillaume, M.; Castronovo, V. Low omega-3 index values and monounsaturated fatty acid levels in early pregnancy: An analysis of maternal erythrocytes fatty acids. Lipids Health Dis. 2018, 17, 1-11. [CrossRef] [PubMed]

14. Gellert, S.; Schuchardt, J.P.; Hahn, A. Higher omega-3 index and DHA status in pregnant women compared to lactating women-Results from a German nation-wide cross-sectional study. Prostaglandins Leukot. Essent. Fatty Acids 2016, 109 , 22-28. [CrossRef]

15. Li, Y.; Li, H.T.; Trasande, L.; Ge, H.; Yu, L.X.; Xu, G.S.; Bai, M.X.; Liu, J.M. DHA in Pregnant and Lactating Women from Coastland, Lakeland, and Inland Areas of China: Results of a DHA Evaluation in Women (DEW) Study. Nutrients 2015, 7, 8723-8732. [CrossRef]

16. Stark, K.D.; Beblo, S.; Murthy, M.; Whitty, J.E.; Buda-Abela, M.; Janisse, J.; Rockett, H.; Martier, S.S.; Sokol, R.J.; Hannigan, J.H.; et al. Alcohol consumption in pregnant, black women is associated with decreased plasma and erythrocyte docosahexaenoic acid. Alcohol. Clin. Exp. Res. 2005, 29, 130-140. [CrossRef]

17. Lim, W.Y.; Chong, M.; Calder, P.C.; Kwek, K.; Chong, Y.S.; Gluckman, P.D.; Godfrey, K.M.; Saw, S.M.; Pan, A.; GUSTO Study Group. Relations of plasma polyunsaturated Fatty acids with blood pressures during the 26th and 28th week of gestation in women of Chinese, Malay, and Indian ethnicity. Medicine 2015, 94, e571. [CrossRef]

18. Wilson, N.A.; Mantzioris, E.; Middleton, P.F.; Muhlhausler, B.S. Influence of sociodemographic, lifestyle and genetic characteristics on maternal DHA and other polyunsaturated fatty acid status in pregnancy: A systematic review. Prostaglandins Leukot. Essent. Fatty Acids 2020, 152, 102037. [CrossRef]

19. Arija, V.; Fargas, F.; March, G.; Abajo, S.; Basora, J.; Canals, J.; Ribot, B.; Aparicio, E.; Serrat, N.; Hernández-Martínez, C.; et al. Adapting iron dose supplementation in pregnancy for greater effectiveness on mother and child health: Protocol of the ECLIPSES randomized clinical trial. BMC Pregnancy Child. 2014, 14, 33. [CrossRef]

20. Iglesias, I.; Arija, V.; Aranda, N.; Aparicio, E.; Serrat, N.; Fargas, F.; Ruiz, F.; Pallejà, M.; Coronel, P.; Gimeno, M.; et al. The Effectiveness of Different Doses of Iron Supplementation and the Prenatal Determinants of Maternal Iron Status in Pregnant Spanish Women: ECLIPSES Study. Nutrients 2019, 11, 2418. [CrossRef]

21. Institut d'Estadística de Catalunya. Classificació Catalana d'Ocupacions 2011 (CCO-2011); Institut d'Estadística de Catalunya: Catalunya, Spain, 2011.

22. Craig, C.L.; Marshall, A.L.; Sjöström, M.; Bauman, A.E.; Booth, M.L.; Ainsworth, B.E.; Pratt, M.; Ekelund, U.; Yngve, A.; Sallis, J.F.; et al. International physical activity questionnaire: 12-Country reliability and validity. Med. Sci. Sports Exerc. 2003, 35, $1381-1395$. [CrossRef] [PubMed]

23. World Health Organization (WHO). Global Dabatase on Body Mass Index. 2006. Available online: http://apps.who.int/bmi/ index.jsp.?introPage=intro_3.html (accessed on 18 January 2019).

24. Trinidad, I.; Fernández, J.; Cucó, G.; Biarnés, E.; Arija, V. Validación de un cuestionario de frecuencia de consumo alimentario corto: Reproducibilidad y validez. Nutr. Hosp. 2008, 23, 242-252.

25. Trichopoulou, A.; Kouris-Blazos, A.; Wahlqvist, M.L.; Gnardellis, C.; Lagiou, P.; Polychronopoulos, E.; Vassilakou, T.; Lipworth, L.; Trichopoulos, D. Diet and overall survival in elderly people. BMJ 1995, 311, 1457-1460. [CrossRef] [PubMed]

26. Trichopoulou, A.; Costacou, T.; Bamia, C.; Trichopoulos, D. Adherence to a Mediterranean diet and survival in a Greek population. N. Engl. J. Med. 2003, 348, 2599-2608. [CrossRef] [PubMed]

27. Jardí, C.; Aparicio, E.; Bedmar, C.; Aranda, N.; Abajo, S.; March, G.; Basora, J.; Arija, V. Food consumption during pregnnacy and post-partum. ECLIPSES Study. Nutrients 2019, 11, 2447. [CrossRef]

28. David, F.; Tienpont, B.; Klee, M.S.; Tripp, P. Automated Sample Preparation for Profiling Fatty Acids in Blood and Plasma Using the Agilent 7693. Agil Appl Note [Internet]. 5990-4822E. Available online: https://www.agilent.com/cs/library/applications/59 90-4822EN.pdf (accessed on 20 January 2021).

29. Mowbray, F.I.; Fox-wasylyshyn, S.M.; El-masri, M.M. Univariate Outliers: A Conceptual Overview for the Nurse Researcher. Can. J. Nurs. Res. 2019, 51, 31-37. [CrossRef]

30. Cousineau, D.; Chartier, S. Outliers detection and treatment: A review. Int. J. Psychol. Res. 2011, 3, 58-67. [CrossRef]

31. Lauritzen, L.; Carlson, S.E. Maternal fatty acid status during pregnancy and lactation and relation to newborn and infant status. Matern. Child Nutr. 2011, 7 (Suppl. 2), 41-58. [CrossRef]

32. Simopoulos, A.P. The importance of the Omega-6/Omega-3 fatty acid ratio in cardiovascular disease and other chronic diseases. Exp. Biol. Med. 2008, 233, 674-688. [CrossRef]

33. Ortega, R.M.; González, L.G.; Villalobos, T.K.; Perea, J.M.; Aparicio, A.; López, A.M. Fuentes alimentarias y adecuación de la ingesta de ácidos grasos omega-3 y omega- 6 en una muestra representativa de adultos españoles [Food sources and adequacy of intake of omega 3 and omega-6 fatty acids in a representative sample of Spanish adults]. Nutr. Hosp. 2013, 28, 2236-2245. (In Spanish).

34. Gómez, C.; Bermejo, L.M.; Loria, V. Importance of a balanced omega 6/omega 3 ratio for the maintenance of health: Nutritional recommendations. Nutr. Hosp. 2011, 26, 323-329. [CrossRef]

35. Bonham, M.P.; Duffy, E.M.; Wallace, J.M.; Robson, P.J.; Myers, G.J.; Davidson, P.W.; Clarkson, T.W.; Shamlaye, C.F.; Strain, J.J. Habitual fish consumption does not prevent a decrease in LCPUFA status in pregnant women (the Seychelles Child Development Nutrition Study). Prostaglandins Leukot. Essent. Fatty Acids 2008, 78, 343-350. [CrossRef] [PubMed] 
36. Otto, S.J.; van Houwelingen, A.C.; Badart-Smook, A.; Hornstra, G. Changes in the maternal essential fatty acid profile during early pregnancy and the relation of the profile to diet. Am. J. Clin. Nutr. 2001, 73, 302-307. [CrossRef]

37. Burdge, G.C. Alpha-linolenic acid metabolism in men and women: Nutritional and biological implications. Curr. Opin. Clin. Nutr. Metab. Care 2004, 7, 37-144. [CrossRef]

38. Postle, A.D.; Al, M.D.; Burdge, G.C.; Hornstra, G. The composition of individual molecular species of plasma phosphatidylcholine in human pregnancy. Early Hum. Dev. 1995, 43, 47-58. [CrossRef]

39. Steenweg-de Graaff, J.; Tiemeier, H.; Ghassabian, A.; Rijlaarsdam, J.; Jaddoe, V.W.; Verhulst, F.C.; Roza, S.J. Maternal Fatty Acid Status During Pregnancy and Child Autistic Traits: The Generation R Study. Am. J. Epidemiol. 2016, 183, 792-799. [CrossRef]

40. Hibbeln, J.R.; Spiller, P.; Brenna, J.T.; Golding, J.; Holub, B.J.; Harris, W.S.; Kris-Etherton, P.; Lands, B.; Connor, S.L.; Myers, G.; et al. Relationships between seafood consumption during pregnancy and childhood and neurocognitive development: Two systematic reviews. Prostaglandins Leukot. Essent. Fatty Acids 2019, 151, 14-36. [CrossRef]

41. Julvez, J.; Méndez, M.; Fernandez-Barres, S.; Romaguera, D.; Vioque, J.; Llop, S.; Ibarluzea, J.; Guxens, M.; Avella-Garcia, C.; Tardón, A.; et al. Maternal Consumption of Seafood in Pregnancy and Child Neuropsychological Development: A Longitudinal Study Based on a Population With High Consumption Levels. Am. J. Epidemiol. 2016, 183, 169-182. [CrossRef] [PubMed]

42. Lauritzen, L.; Brambilla, P.; Mazzocchi, A.; Harsløf, L.B.S.; Ciappolino, V.; Agostoni, C. DHA Effects in Brain Development and Function. Nutrients 2016, 8, 6. [CrossRef]

43. Montes, R.; Chisaguano, A.M.; Castellote, A.M.; Morales, E.; Sunyer, J.; López-Sabater, M.C. Fatty-acid composition of maternal and umbilical cord plasma and early childhood atopic eczema in a Spanish cohort. Eur. J. Clin. Nutr. 2013, 67, 658-663. [CrossRef]

44. Rodríguez-Bernal, C.; Ramón, R.; Quiles, J.; Murcia, M.; Navarrete-Muñoz, E.M.; Vioque, J.; Ballester, F.; Regablito, M. Dietary intake in pregnant women in a Spanish Mediterranean area: As good as it is supposed to be? Public Health Nutr. 2012, 16, 1379-1389. [CrossRef] [PubMed]

45. Stråvik, M.; Jonsson, K.; Hartvigsson, O.; Sandin, A.; Wold, A.E.; Sandberg, A.-S.; Barman, M. Food and Nutrient Intake during Pregnancy in Relation to Maternal Characteristics: Results from the NICE Birth Cohort in Northern Sweden. Nutrients 2019, 11, 1680. [CrossRef] [PubMed]

46. Doyle, I.M.; Borrmann, B.; Grosser, A.; Razum, O.; Spallek, J. Determinants of dietary patterns and diet quality during pregnancy: A systematic review with narrative synthesis. Public Health Nutr. 2017, 20, 1009-1028. [CrossRef] [PubMed]

47. Savard, C.; Lemieux, S.; Carbonneau, É.; Provencher, V.; Gagnon, C.; Robitaille, J.; Morisset, A.S. Trimester-Specific Assessment of Diet Quality in a Sample of Canadian Pregnant Women. Int. J. Environ. Res. Public Health 2019, 16, 311. [CrossRef] [PubMed]

48. McKinnon, L.; Giskes, K.; Turrell, G. The contribution of three components of nutrition knowledge to socio-economic differences in food purchasing choices. Public Health Nutr. 2014, 17, 1814-1824. [CrossRef] [PubMed]

49. Hakli, G.; Asil, E.; Uçar, A.; Ozdogan, Y.; Yilmaz, M.Y.; Ozçelik, A.O.; Surucuo, M.S.; Çakiro, F.P.; Akan, L.S. Nutritional Knowledge and Behavior of Adults: Their Relations with Sociodemographic Factors. Pak. J. Nutr. 2016, 15, 532-539. [CrossRef]

50. Jahns, L.; Raatz, S.K.; Johnson, L.K.; Kranz, S.; Silverstein, J.T.; Picklo, M.J. Intake of Seafood in the US Varies by Age, Income, and Education Level but Not by Race-Ethnicity. Nutrients 2014, 6, 6060-6075. [CrossRef]

51. Nordgren, T.M.; Lyden, E.; Anderson-Berry, A.; Hanson, C. Omega-3 Fatty Acid Intake of Pregnant Women and Women of Childbearing Age in the United States: Potential for Deficiency? Nutrients 2017, 9, 197. [CrossRef]

52. Dubé, E.; Gravel, A.; Martin, C.; Desparois, G.; Moussa, I.; Ethier-Chiasson, M.; Forest, J.C.; Giguère, Y.; Masse, A.; Lafond, J. Modulation of fatty acid transport and metabolism by maternal obesity in the human full-term placenta. Biol. Reprod. 2012, 87, 14, 1-11. [CrossRef]

53. Sowell, K.D.; Holt, R.R.; Uriu-Adams, J.Y.; Chambers, C.D.; Coles, C.D.; Kable, J.A.; Yevtushok, L.; Zymak-Zakutnya, N.; Wertelecki, W.; Keen, C.L.; et al. Altered Maternal Plasma Fatty Acid Composition by Alcohol Consumption and Smoking during Pregnancy and Associations with Fetal Alcohol Spectrum Disorders. J. Am. Coll. Nutr. 2020, 39, 249-260. [CrossRef]

54. Agostoni, C.; Riva, E.; Giovannini, M.; Pinto, F.; Colombo, C.; Risé, P.; Galli, C.; Marangoni, F. Maternal smoking habits are associated with differences in infants' long-chain polyunsaturated fatty acids in whole blood: A case-control study. Arch. Dis. Child. 2008, 93, 414-418. [CrossRef]

55. Baldassarre, D.; Amato, M.; Frigerio, B.; Ghezzi, S.; Colombo, C.; Castelnuovo, S.; Ravani, A.; Sansaro, D.; Tremoli, E.; Sirtori, C.R.; et al. Impact of cigarette smoking on the plasma fatty acid profile and their interaction in determining the burden of subclinical atherosclerosis. Nutrafoods 2014, 13, 159-167. [CrossRef]

56. Sinzinger, H.; Kaliman, J.; Oguogho, A. Eicosanoid production and lymphatic responsiveness in human cigarette smokers compared with non-smokers. Lymphology 2000, 33, 24-31. [PubMed]

57. Gouveia-Figueira, S.; Martens, D.S.; Nawrot, T.S.; Nording, M.L. Cord blood eicosanoid signatures and newborn gestational age. Prostaglandins Other Lipid Mediat. 2017, 133, 123-127. [CrossRef] [PubMed]

58. Ribot, B.; Isern, R.; Hernández-Martínez, C.; Canals, J.; Aranda, N.; Arija, V. Impacto del tabaquismo, la exposición pasiva al tabaco y el dejar de fumar sobre la salud del recien nacido [Effects of tobacco habit, second-hand smoking and smoking cessation during pregnancy on newborn's health]. Med. Clin. 2014, 143, 57-63. [CrossRef]

59. Pawlosky, R.J.; Salem, J.N. Perspectives on alcohol consumption: Liver polyunsaturated fatty acids and essential fatty acid metabolism. Alcohol 2004, 34, 27-33. [CrossRef] [PubMed] 
60. Navas-Carretero, S.; Pérez-Granados, A.M.; Sarriá, B.; Carbajal, A.; Pedrosa, M.M.; Roe, M.A.; Fairweather-Tait, S.J.; Vaquero, M.P. Oily fish increases iron bioavailability of a phytate rich meal in young iron deficient women. J. Am. Coll. Nutr. 2008, $27,96-101$. [CrossRef]

61. Zanzoni, S.; Pagano, K.; D’Onofrio, M.; Assfalg, M.; Ciambellotti, S.; Bernacchioni, C.; Turano, P.; Aime, S.; Ragona, L.; Molinari, H. Unsaturated Long-Chain Fatty Acids Are Preferred Ferritin Ligands That Enhance Iron Biomineralization. Chemistry 2017, 23, 9879-9887. [CrossRef]

62. Sun, Q.; Ma, J.; Campos, H.; Hankinson, S.E.; Hu, F.B. Comparison between plasma and erythrocyte fatty acid content as biomarkers of fatty acid intake in US women. Am. J. Clin. Nutr. 2007, 86, 74-81. [CrossRef]

63. Vlaardingerbroek, H.; Hornstra, G. Essential fatty acids in erythrocyte phospholipids during pregnancy and at delivery in mothers and their neonates: Comparison with plasma phospholipids. Prostaglandins Leukot. Essent. Fatty Acids 2004, 71, 363-374. [CrossRef]

64. Conway, M.C.; McSorley, E.M.; Mulhern, M.S.; Strain, J.J.; van Wijngaarden, E.; Yeates, A.J. Influence of fatty acid desaturase (FADS) genotype on maternal and child polyunsaturated fatty acids (PUFA) status and child health outcomes: A systematic review. Nutr. Rev. 2020, 78, 627-646. [CrossRef] [PubMed] 